PREPARED FOR THE U.S. DEPARTMENT OF ENERGY, UNDER CONTRACT DE-AC02-76CH03073

PPPL-3568

PPPL-3568

UC-70

\title{
Electron Bernstein Wave Research on CDX-U and NSTX
}

G. Taylor, P.C. Efthimion, B. Jones, J.C. Hosea, R. Kaita, B.P. LeBlanc, R. Majeski, T. Munsat, C.K. Phillips, J. Spaleta, J.R. Wilson, D. Rasmussen, G. Bell, T.S. Bigelow, M.D. Carter, D.W. Swain, J.B. Wilgen, A.K. Ram, A. Bers, R.W. Harvey, C.B. Forest

May 2001

NM|

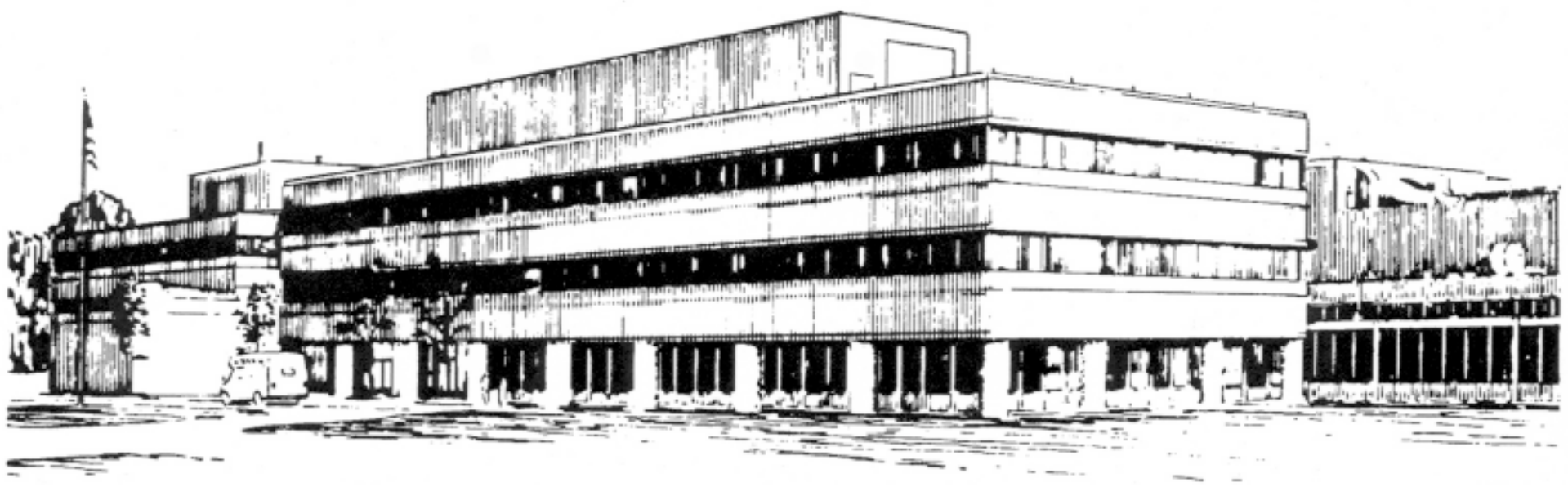

PRINCETON PLASMA PHYSICS LABORATORY PRINCETON UNIVERSITY, PRINCETON, NEW JERSEY 


\section{PPPL Reports Disclaimer}

This report was prepared as an account of work sponsored by an agency of the United States Government. Neither the United States Government nor any agency thereof, nor any of their employees, makes any warranty, express or implied, or assumes any legal liability or responsibility for the accuracy, completeness, or usefulness of any information, apparatus, product, or process disclosed, or represents that its use would not infringe privately owned rights. Reference herein to any specific commercial product, process, or service by trade name, trademark, manufacturer, or otherwise, does not necessarily constitute or imply its endorsement, recommendation, or favoring by the United States Government or any agency thereof. The views and opinions of authors expressed herein do not necessarily state or reflect those of the United States Government or any agency thereof.

\section{Availability}

This report is posted on the U.S. Department of Energy's Princeton Plasma Physics Laboratory Publications and Reports web site in Calendar Year 2001. The home page for PPPL Reports and Publications is: http://www.pppl.gov/pub_report/

DOE and DOE Contractors can obtain copies of this report from:

U.S. Department of Energy

Office of Scientific and Technical Information

DOE Technical Information Services (DTIS)

P.O. Box 62

Oak Ridge, TN 37831

Telephone: (865) 576-8401

Fax: (865) 576-5728

Email: reports@adonis.osti.gov

This report is available to the general public from:

National Technical Information Service

U.S. Department of Commerce

5285 Port Royal Road

Springfield, VA 22161

Telephone: 1-800-553-6847 or

(703) 605-6000

Fax: (703) 321-8547

Internet: http://www.ntis.gov/ordering.htm 


\title{
Electron Bernstein Wave Research on CDX-U and NSTX
}

G. Taylor, P.C. Efthimion, B. Jones, J.C. Hosea, R. Kaita, B.P. LeBlanc, R. Majeski, T. Munsat, C.K. Phillips, J. Spaleta, J.R. Wilson

Plasma Physics Laboratory, Princeton University, Princeton, NJ 08543

D. Rasmussen, G. Bell, T.S. Bigelow, M.D. Carter, D.W. Swain, J.B. Wilgen

Oak Ridge National Laboratory, Oak Ridge, TN 37831

A.K. Ram, A. Bers

Plasma Fusion Center, MIT, Cambridge, MA 02139

R.W. Harvey

CompX, Del Mar, CA 92014

C.B. Forest

Physics Department, University of Wisconsin, Madison, WI 53706

\begin{abstract}
Mode-converted electron Bernstein waves (EBWs) potentially allow the measurement of local electron temperature $\left(\mathrm{T}_{\mathrm{e}}\right)$ and the implementation of local heating and current drive in spherical torus (ST) devices, which are not directly accessible to low harmonic electron cyclotron waves. This paper reports on the measurement of X-mode radiation mode-converted from EBWs observed normal to the magnetic field on the midplane of the CDX-U and NSTX ST plasmas. The radiation temperature of the EBW emission was compared to $\mathrm{T}_{\mathrm{e}}$ measured by Thomson scattering and Langmuir probes. EBW mode conversion efficiencies of over $20 \%$ were measured on both CDX-U and NSTX. Sudden increases of mode conversion efficiency, of over a factor of three, were observed at H-mode transitions on NSTX, when the measured edge density profile steepened. The EBW mode conversion efficiency was found to depend on the density gradient at the mode conversion layer in the plasma scrape off, consistent with theoretical predictions. The EBW emission source was determined by a perturbation technique to be localized at the electron cyclotron resonance layer and was successfully used for radial transport studies. Recently, a new in-vessel antenna and Langmuir probe array were installed on CDX-U to better characterize and enhance the EBW mode conversion process. The probe incorporates a local adjustable limiter to control and maximize the mode conversion efficiency in front of the antenna by modifying the density profile in the plasma scrape off where fundamental EBW mode conversion occurs. Initial results show that the mode conversion efficiency can be increased to $\sim 100 \%$ when the local limiter is inserted near the mode conversion layer. Plans for future EBW research, including EBW heating and current drive studies, are discussed.
\end{abstract}

\section{INTRODUCTION}

This paper reports the status of electron Bernstein wave (EBW) research on the CDX-U [1] and NSTX [2] magnetically confined, spherical torus (ST) plasmas at the Princeton Plasma Physics Laboratory. ST plasmas operate at relatively low magnetic fields and high densities. Consequently fundamental and low harmonic electron cyclotron waves cannot propagate. As a result, standard electron temperature $\left(\mathrm{T}_{\mathrm{e}}\right)$ profile diagnostics that utilize fundamental or second harmonic electron cyclotron emission (ECE) cannot be used. Further, established electron cyclotron heating $(\mathrm{ECH})$ and electron cyclotron current drive (ECCD) techniques cannot be utilized on these ST machines.

EBWs are electrostatic waves that have no high density cutoffs, so they can propagate in ST plasmas. They also exhibit very high optical thickness $(\tau)$ at the electron cyclotron resonances [3]. For example, $\tau \sim 300$ on CDX-U and $\tau \sim 3000$ on NSTX compared to $\tau \sim 1-100$ for ECE in conventional high magnetic field, high 
aspect ratio plasma devices. Although EBWs can only exist inside the upper hybrid resonance (UHR) layer that surrounds ST plasmas, under certain conditions they can mode-convert to electromagnetic waves near the plasma edge. This potentially allows the measurement of local $T_{e}$ with EBWs, and the implementation of EBW heating and current drive. Measuring the mode conversion efficiency of the EBW emission yields important information about the viability of EBW heating and current drive.

There are two EBW mode conversion processes. The first involves the conversion of EBWs to the slow X-mode at the UHR [4-6]. The left hand cutoff of the slow X-mode, the UHR, and the right hand cutoff of the fast X-mode form a cutoff-resonance-cutoff triplet allowing the slow X-mode to tunnel through the UHR to the fast $\mathrm{X}$-mode. This is the mode conversion process investigated on CDX-U and NSTX. In this paper we will refer to this as B-X mode conversion. The maximum mode conversion efficiency for $\mathrm{k}_{/ /}=0$ is given by [6]:

$$
C_{\max }=4 e^{-\pi \eta}\left(1-e^{-\pi \eta}\right)
$$

where $\eta$ is the tunneling parameter. For magnetic scale lengths much greater than the density scale length at the UHR [6]:

$$
\eta \approx \frac{1}{2}\left[\omega_{c e} L_{n} / c\right], \text { where: } L_{n}=\left|\frac{n_{e}}{d n_{e} / d R}\right|_{U H R}
$$

Here $\omega_{\text {ce }}$ is the electron cyclotron frequency at the UHR, $n_{e}$ is the electron density and $c$ is the velocity of light. As can be seen from equations (1) and (2), the B-X mode conversion efficiency is very sensitive to the electron density scale length at the UHR layer, which is resonant with the EBW emission. On CDX-U and NSTX the maximum mode conversion efficiency typically occurs for $\mathrm{L}_{\mathrm{n}} \sim 0.5-1 \mathrm{~cm}$. B-X mode conversion is particularly well suited for ST plasmas where the UHR layer can be just a few millimeters from the right hand cutoff, as shown in Fig. 1.

The second mode conversion process requires the coincidence of the $\mathrm{X}$-mode and O-mode cutoffs [7-11]. This process, referred to here as $\mathrm{B}-\mathrm{X}-\mathrm{O}$ mode conversion, has been previously studied on Wendelstein 7-AS [12,13] and requires an oblique view of the plasma at a specific angle. The $\mathrm{B}-\mathrm{X}-\mathrm{O}$ emission leaves the plasma through an angular window with a transmission function given by $[9,11]$ :

$$
T\left(N_{\perp}, N_{/ /}\right)=\exp \left\{-\pi k_{o} L_{n} \sqrt{(Y / 2)}\left[2(1+Y)\left(N_{/ /, o p t}-N_{/ /}\right)^{2}+N_{\perp}^{2}\right]\right\}
$$

where: $N_{/ /, o p t}^{2}=[Y /(Y+1)], Y=\left(\omega_{c e} / \omega\right), \omega_{\text {ce }}$ is evaluated at the cutoff and $\omega$ is the wave frequency.

For CDX-U and NSTX this B-X-O emission window is located at about $35^{\circ}$ from the antenna axis at the midplane of the antenna. As shown in equation (3), the emission window has a width that depends on $\mathrm{L}_{\mathrm{n}}$ at the $\mathrm{X}$-mode and $\mathrm{O}$-mode cutoffs. It can also potentially contribute to the measured X-mode emission if there is polarization scrambling of the $\mathrm{O}$-mode emission as a result of reflections.

Section 2 of this paper summarizes the status of EBW emission measurements on CDX-U and NSTX. Section 3 presents initial measurements from a new invacuum antenna with a local limiter and section 4 reviews plans for implementing EBW heating and current drive on CDX-U and NSTX. 


\section{EBW EMISSION MEASUREMENTS}

EBW measurements on CDX-U and NSTX have so far focused on validating the physics of the $\mathrm{B}-\mathrm{X}$ mode conversion process. We have measured the mode conversion efficiency by comparing the EBW radiation temperature to $T_{e}$ measured by standard diagnostics, such as Thomson scattering and Langmuir probes, and verified the localization of the EBW emission source by employing cold gas perturbations to locally modulate $\mathrm{T}_{\mathrm{e}}$.

\begin{tabular}{|c|c|c|}
\hline & NSTX & CDX-U \\
\hline $\mathbf{R}(\mathbf{c m})$ & 85 & 33.5 \\
\hline $\mathbf{a}(\mathbf{c m})$ & 68 & 22.5 \\
\hline $\mathbf{I}_{\mathbf{p}}$ & $\sim 1 \mathrm{MA}$ & $\sim 70 \mathrm{kA}$ \\
\hline $\mathbf{B}_{\mathbf{t}}(\mathbf{T})$ & $0.3-0.6$ & $\sim 0.2$ \\
\hline $\mathbf{T}_{\mathbf{e}}(\mathbf{0})$ & $0.4-1.1 \mathrm{keV}$ & $10-100 \mathrm{eV}$ \\
\hline $\mathbf{n}_{\mathbf{e}}(\mathbf{0})$ & $\sim 10^{14} \mathrm{~cm}^{-3}$ & $\sim 3 \times 10^{13} \mathrm{~cm}^{-3}$ \\
\hline
\end{tabular}

Table 1 NSTX and CDX-U parameters.

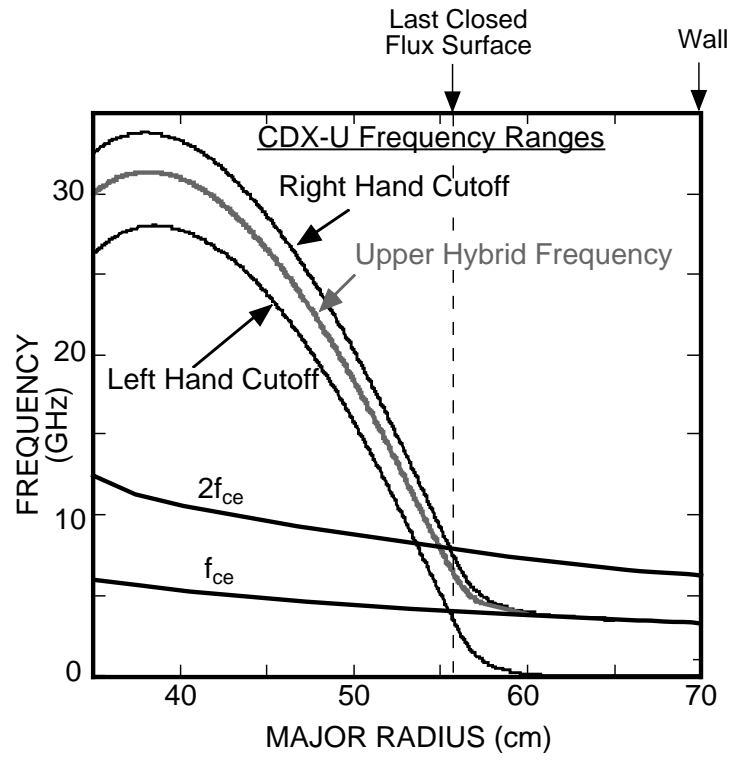

Figure $1 \mathrm{CDX}-\mathrm{U}$ characteristic frequencies.

Mode-converted EBW emission from NSTX and CDX-U was measured normal to the magnetic field with both frequency tunable and fast frequency scanning microwave radiometry [14]. Broadband, dual ridged antennas on both machines were oriented to accept predominantly X-mode polarized emission during the plasma current flat top. The antennas were mounted outside the vacuum vessel and viewed the plasma through a vacuum window. Table 1 shows some of the major parameters of CDX-U and NSTX. Figure 1 shows typical characteristic frequencies for CDX-U. On CDX-U and NSTX, $\omega_{\mathrm{pe}} / \omega_{\mathrm{ce}}$ is typically 5-10 at the magnetic axis and $\omega_{\mathrm{pe}}>\omega_{\mathrm{ce}}$ beyond the last closed flux surface on the outboard side of the plasma. Second harmonic EBWs from the plasma core modeconvert to X-mode near the last closed flux surface (R 56 cm on CDX-U) and fundamental EBWs mode-convert between the last closed flux surface and the vacuum vessel wall $(\mathrm{R}=70 \mathrm{~cm}$ on $\mathrm{CDX}-\mathrm{U})$.

On CDX-U, a radially scanned Langmuir triple probe measured the edge electron density and temperature profiles and a multi-point Thomson scattering diagnostic measured the core electron temperature and density. The EBW radiometers were calibrated absolutely with a Dicke-switched blackbody calibration source. Figure 2 shows a comparison between the $\mathrm{T}_{\mathrm{e}}$ profile and the EBW radiation temperature $\left(\mathrm{T}_{\mathrm{rad}}\right)$ profile, assembled from a sequence of similar CDX-U discharges. On CDX-U, the measured EBW mode conversion efficiency, $\mathrm{T}_{\mathrm{rad}} / \mathrm{T}_{\mathrm{e}}$, has been typically in the range of $10-20 \%$. Similar values have been seen so far on NSTX. 


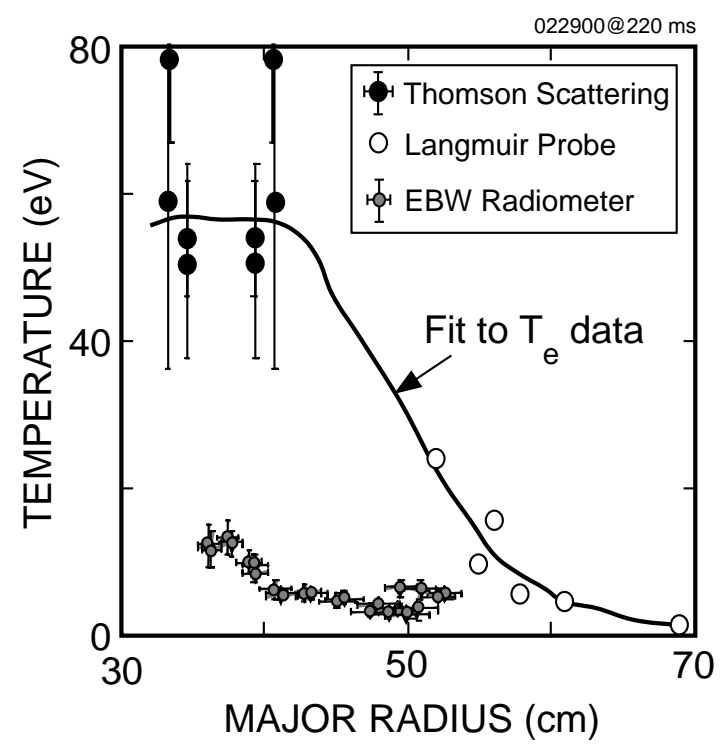

Figure 2 Comparison of $\mathrm{T}_{\mathrm{e}}$ and $\mathrm{EBW} \mathrm{T}_{\mathrm{rad}}$ on CDX-U.

The radial localization of the EBW emission source was confirmed by perturbing the $T_{e}$ profile with a series of cold gas puffs, a technique used earlier by Laqua et al. [13]. The cold gas puffs locally cooled the plasma edge producing an inward propagating temperature response that was measured by the EBW radiometer. The EBW $\mathrm{T}_{\text {rad }}$ was mapped to major radius assuming that it was emitted from the second harmonic EBW resonance layer. The delay in the arrival time of the temperature pulse was found to be a maximum for EBWs emitted from the magnetic axis, as shown in Fig. 3. The delay versus radius in the plasma core is consistent with an electron diffusivity of $2 \mathrm{~m}^{2} \mathrm{~s}^{-1}$. The reasonable fit between the data and the model in Fig. 3 is consistent with diffusive thermal transport near the core. The thermal diffusivity is apparently much higher in the outer regions of the discharge [15].

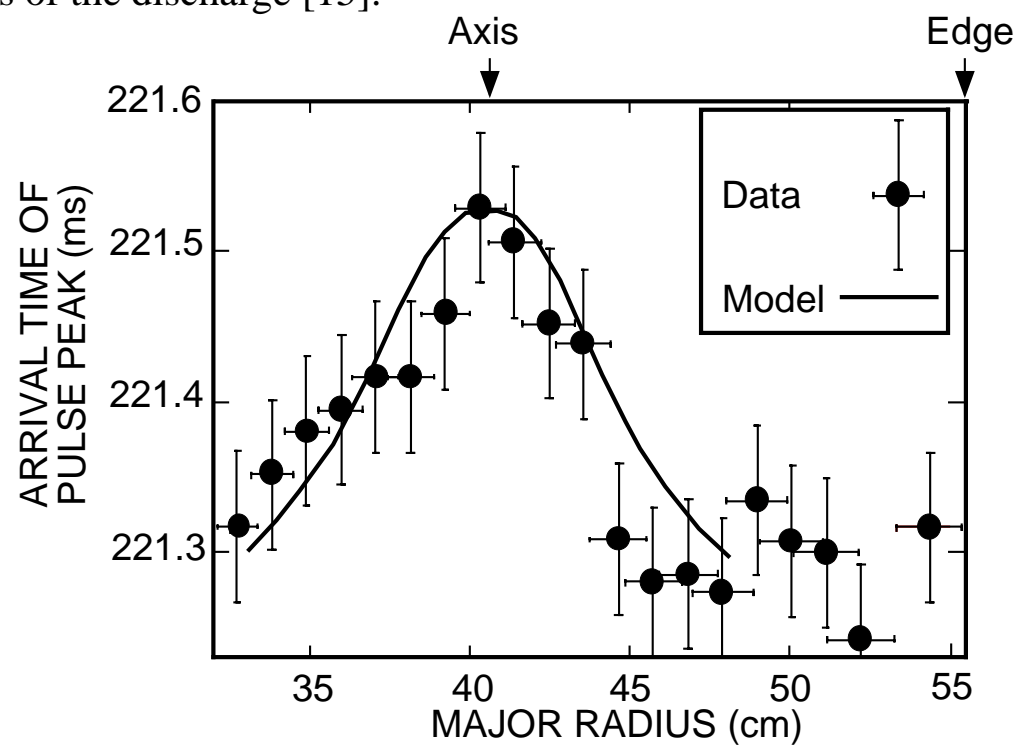

Figure 3 The delay in the peak of the EBW $\mathrm{T}_{\text {rad }}$ pulse is maximum at the magnetic axis following a cold pulse perturbation, as expected. A model prediction for $\chi=2 \mathrm{~m}^{2} \mathrm{~s}^{-1}$ is shown that gives a reasonable fit to the data in the core. 
During neutral-beam-heated NSTX plasmas that contain H-mode transitions, the mode-converted EBW emission is observed to increase by over a factor three, as shown in Fig. 4. The increase in EBW emission is coincident with steepening of the edge density profile during the $\mathrm{H}$-mode. EBW emission data and $\mathrm{L}_{\mathrm{n}}$ data from Thomson scattering were analyzed for the H-mode plasma shown in Fig. 4.

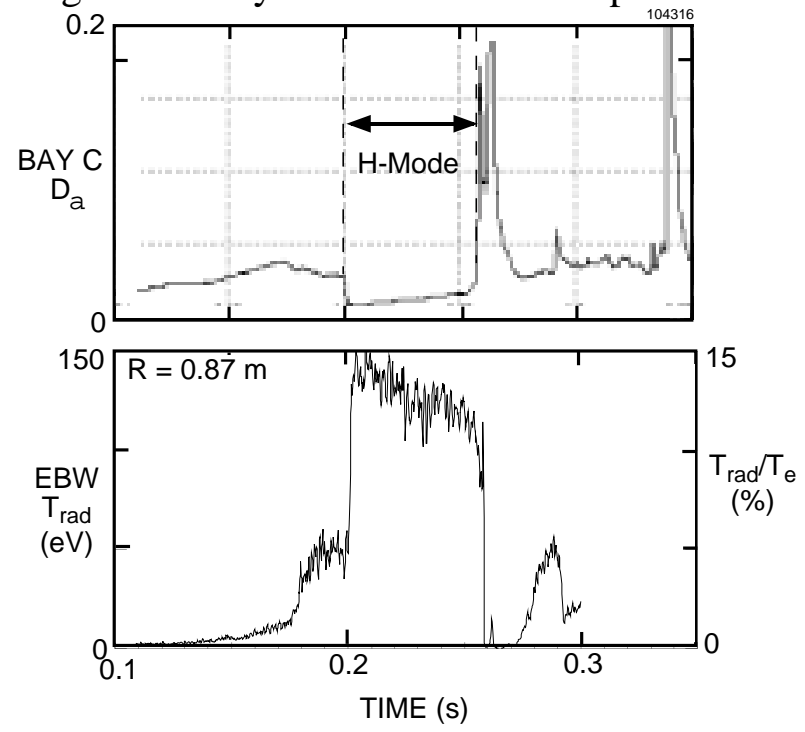

Figure 4 (a) Time evolution of $\mathrm{D}_{\alpha}$ emission and (b) $16 \mathrm{GHz}$ fundamental EBW $\mathrm{T}_{\text {rad }}$ during a neutral-beam-heated NSTX plasma with an H-mode phase.

Good agreement was found between the measured $\mathrm{T}_{\mathrm{rad}} / \mathrm{T}_{\mathrm{e}}$ and the calculated mode conversion efficiency during the $\mathrm{H}$-mode phase of the discharge. The fundamental EBW emission at $16 \mathrm{GHz}$ from $\mathrm{R}=87 \mathrm{~cm}$, shown in Fig. 4(b), modeconverts at a density of $2.4 \times 10^{12} \mathrm{~cm}^{-3}$. Thomson scattering density profile data at $230 \mathrm{~ms}$ indicate that this density lies at major radius, $\mathrm{R}=148 \mathrm{~cm}$, in the scrape off region. An exponential fit to the density data in the scrape off yields $L_{n}=1.5 \mathrm{~cm}$, resulting in a calculated $\mathrm{B}-\mathrm{X}$ mode conversion efficiency from equation (1) of $8 \%$. B-X-O mode conversion may also contribute to the EBW radiometer signal if there is polarization scrambling from reflections. Evidence for substantial depolarization due to reflections has already been noted during experiments with a similar antenna geometry on CDX-U [14]. The maximum contribution from B$\mathrm{X}-\mathrm{O}$ conversion was calculated by combining the $\mathrm{B}-\mathrm{X}-\mathrm{O}$ angular emission window from equation (3) with the measured antenna pattern. The B-X-O conversion, with complete depolarization, could provide an additional $\mathrm{T}_{\mathrm{rad}} / \mathrm{T}_{\mathrm{e}} \sim 3 \%$, so that the combined total is in reasonable agreement with the observed $\mathrm{T}_{\mathrm{rad}} / \mathrm{T}_{\mathrm{e}}$ value of $13 \%$. Before the $\mathrm{H}$-mode, when the mode conversion efficiency from B-X conversion is negligible, as a result of the less steep density gradient at the last closed flux surface, the calculations are only consistent with the measured 2-6\% $\mathrm{T}_{\mathrm{rad}} / \mathrm{T}_{\mathrm{e}}$ if all the emission comes from the depolarized B-X-O mode conversion.

\section{INITIAL LIMITER-ANTENNA EMISSION MEASUREMENTS}

A critical requirement for a viable EBW $T_{e}$ diagnostic is that $L_{n}$ be continuously and reliably characterized in the vicinity of the UHR layer to 
accurately deduce $\mathrm{T}_{\mathrm{e}}$ at the EBW emission layer. Rather than accepting the scale length created in the machine, it has been realized that a local adjustable limiter can be used to optimize $\mathrm{L}_{\mathrm{n}}$. To address these issues an in-vacuum, radially scannable antenna/Langmuir probe assembly was designed and recently installed on CDX-U with the intent to more precisely investigate the physics of B-X mode conversion. The antenna/probe assembly has its own limiter surrounding it. A schematic of the new antenna/probe assembly is shown in Fig. 5. An array of six radially staggered Langmuir probes allows continuous monitoring of the density profile in the immediate vicinity of the antenna. The probes can also be used as electrostatic antennas to directly detect the EBW wave inside the UHR. The horn antenna is a quad ridged, broadband design that can simultaneously measure $\mathrm{O}$ mode and X-mode emission. Two local boron nitride limiters (Fig. 6) surround the antenna and are independently adjustable to optimize the density scale length in front of the antenna for maximum mode conversion efficiency. Since the fundamental $\mathrm{EBW}$ on $\mathrm{CDX}-\mathrm{U}$ converts to X-mode between the last closed flux surface and the vacuum vessel wall (Fig. 1), the local boron nitride limiters can be positioned to optimize the fundamental EBW conversion to X-mode, without perturbing the plasma.

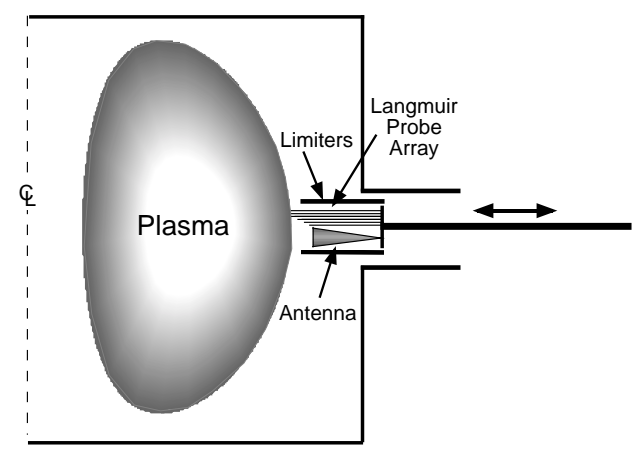

Figure 5 Schematic of the radially scanned antenna/probe array assembly on CDX-U.

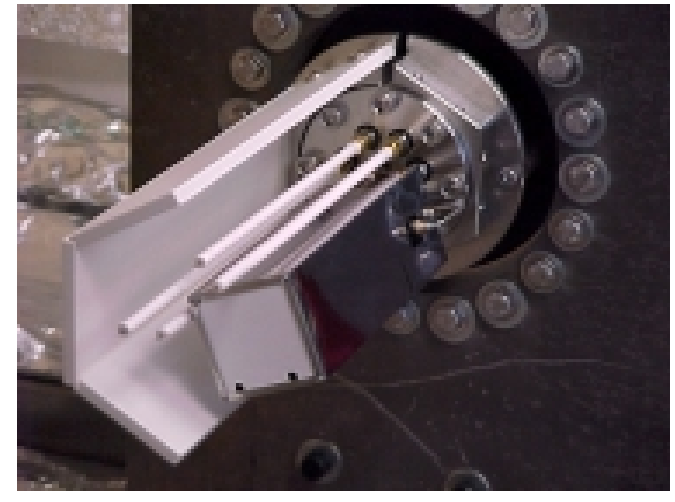

Figure 6 Photo of probe head showing antenna and four probes, with one boron nitride limiter removed.

Initial results from the antenna/probe array show that the mode conversion efficiency can be increased to about $100 \%$ when the local limiter is inserted near the mode conversion layer. Although analysis of initial data from the probe is continuing, it is apparent that the data shows more than an order of magnitude increase in the fundamental mode-converted EBW emission when the local limiter is moved near the mode conversion layer. Comparison between the fundamental EBW $\mathrm{T}_{\text {rad }}$ and $\mathrm{T}_{\mathrm{e}}$ measured by Thomson scattering at the EBW emission layer show $\mathrm{T}_{\mathrm{rad}} / \mathrm{T}_{\mathrm{e}}$ approaching $100 \%$. The use of a limiter outside the last closed flux surface enables the efficient coupling of mode converted EBWs and can lead to a practical electron temperature diagnostic and efficient EBW current drive and heating of high $\beta$ plasmas.

\section{PLANS FOR EBW HEATING AND CURRENT DRIVE}

Demonstrating the ability to establish high X-B mode conversion efficiency is even more critical for the practical implementation of EBW current drive and heating than for an EBW $\mathrm{T}_{\mathrm{e}}$ diagnostic. Launcher designs that incorporate a local limiter to steepen and optimize the density scale length at the UHR layer for maximum EBW mode conversion efficiency are presently being investigated. 
Fundamental EBW heating and current drive may be particularly attractive for an ST plasma since the UHR layer is in the scrape off, so the local limiter does not need to extend inside the last closed flux surface. On CDX-U, experiments to study EBW current drive and heating will begin this year. CDX-U provides an excellent test bed for developing launcher designs that might be used in the future on NSTX [16-18] or other devices. During the coming year a microwave source will be installed on CDX-U as part of an EBW heating and current drive system. Initial calculations show that, if the $\mathrm{X}$-B conversion efficiency can be increased to $50 \%$, this system could drive $\sim 30 \mathrm{kA}$, or about $50 \%$ of the total plasma current on CDX-U.

As has previously been pointed out [19], EBW current drive may be particularly attractive for ST devices and other high $\beta$ plasmas. Steering of the EBW waves can be accomplished by taking advantage of the relatively strong poloidal field and large magnetic shear present in ST plasmas. Significant $n_{/ \prime}$ shifts can be produced in EBWs launched with $\mathrm{n}_{l}=0$ from a launcher location poloidally displaced above and below the plasma midplane [6]. Figure 7 shows the poloidally-projected EBW ray trajectories calculated by GENRAY [20] for two launch frequencies and poloidal angles for the NSTX EFIT equilibrium produced during the H-mode plasma discussed earlier (Fig. 4). The trajectory of $16 \mathrm{GHz}$ (bold lines) and $12 \mathrm{GHz}$ (thin lines) EBWs launched at a poloidal angle $\pm 20^{\circ}$ from the midplane are shown. Plotting of the rays ends when $>99 \%$ of the power has been deposited in the plasma. In all four cases the rays bend towards the midplane.

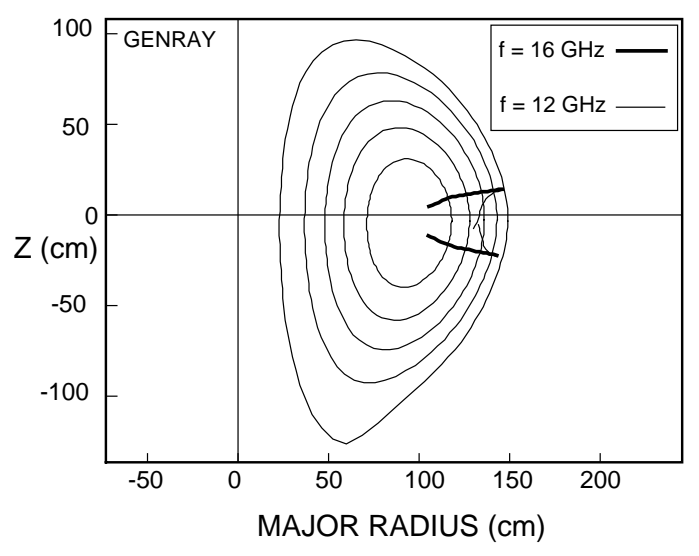

Figure 7 Poloidal cross section of NSTX showing path of EBW rays launched $20^{\circ}$ above and below midplane, at 12 and $16 \mathrm{GHz}$.

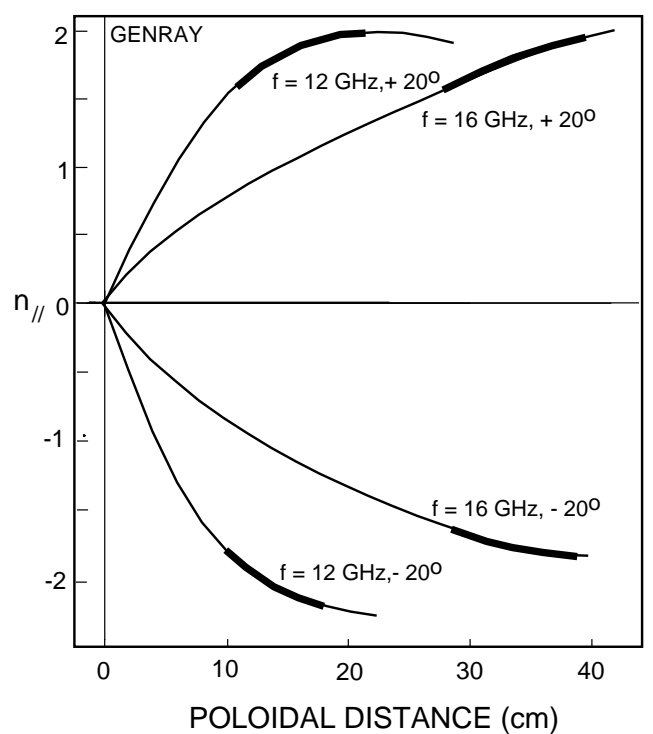

Figure 8 EBW rays launched with $\mathrm{n}_{/ /}=0$ damp where ray path is shown thickened.

Figure 8 shows a plot of $\mathrm{n}_{/ /}$versus the poloidally-projected distance along each ray. $99 \%$ of the EBW power is deposited where the ray is plotted in bold. The launch frequency determines the radial location of the deposition and the poloidal launch angle determines the $\mathrm{n}_{/ /}$of the absorbed EBWs. The current drive efficiency is improved with high $\mathrm{n}_{/ /}$EBWs. Because the damping of EBWs is by cyclotron damping, trapped particle effects need to by taken into account. A detailed EBW current drive analysis is now being performed with the CQL3D Fokker-Planck code [21] using various launch frequencies and launcher locations for relevant CDX-U and NSTX equilibria. Results from the EBW heating and 
current drive experiments on CDX-U and other ST devices will provide important data for the design of a more powerful system being planned for installation on NSTX in 2004-5. This system could produce EBW-driven currents up to 400kA, for X-B conversion efficiencies $>50 \%$.

\section{ACKNOWLEDGMENTS}

This work was supported by US Department of Energy contract no. DEAC02-76CH03073 and by a Department of Energy research grant which is part of

a program to encourage innovations in magnetic fusion energy diagnostic systems.

\section{REFERENCES}

[1] Menard, J., et al., Phys. Plasmas 6, 2002 (1999).

[2] Ono, M., et al., Proc. $17^{\text {th }}$ IAEA Fus. Energy Conf. (IAEA, Vienna, 1999), Vol. 3, p. 1135.

[3] Efthimion, P.C., et al., Rev. Sci. Instrum. 70, 1018 (1999).

[4] Nakajima, S. and Abe, H., Phys. Rev. A 38, 4373 (1988).

[5] Sugai, H., Phys. Rev. Lett. 47, 1899 (1981).

[6] Ram, A.K. and Schultz, S.D., Physics of Plasmas 7, 4084 (2000).

[7] Preinhaelter, J. and Kopécky, V., J. Plasma Phys. 10, 1 (1973).

[8] Weitzner, H. and Batchelor, D.B., Phys. Fluids 22, 1355 (1979).

[9] Mjølhus, E., J. Plasma Phys. 31, 7 (1984).

[10] Nakajima, S. and Abe, H., Phys. Lett. A 124, 295 (1987).

[11] Hansen, F.R., et al., J. Plasma Phys. 39, 319 (1988).

[12] Laqua, H.P., et al., Phys. Rev. Lett. 78, 3467 (1997).

[13] Laqua, H.P., et al., Phys. Rev. Lett. 81, 2060 (1998).

[14] Taylor, G., et al., Rev. Sci. Instrum. 72, 285 (2001).

[15] Munsat, T., et al., "Transient Transport Experiments in the CDX-U Spherical Torus", to be submitted to Phys. Plasmas (2001).

[16] Carter, M.D., et al., AIP Conf. Proc. 485, 407 (1999).

[17] Bigelow, T.S., et al., AIP Conf. Proc. 403, 211 (1999).

[18] Batchelor, D.B. and Bigelow, T.S., AIP Conf. Proc. 403, 215 (1999).

[19] Forest, C.B., et al., Phys. Plasmas 7, 1352 (2000).

[20] Smirnov, A.P. and Harvey, R.W., Bull. Am. Phys. Soc. 40, 1837 (1995).

[21] Harvey, R.W. and McCoy, M.G., Proc. IAEA Tech. Com. on Advances in Simulation and Modeling of Thermonuclear Plasmas, Montreal, Quebec (IAEA, Vienna, 1993) p. 489. 


\section{External Distribution}

Plasma Research Laboratory, Australian National University, Australia

Professor I.R. J ones, Flinders University, Australia

Professor J oão Canalle, Instituto de Fisica DEQ/IF - UERJ , Brazil

Mr. Gerson O. Ludwig, Instituto Nacional de Pesquisas, Brazil

Dr. P.H. Sakanaka, Instituto Fisica, Brazil

The Librarian, Culham Laboratory, England

Library, R61, Rutherford Appleton Laboratory, England

Mrs. S.A. Hutchinson, JET Library, England

Professor M.N. Bussac, Ecole Polytechnique, France

Librarian, Max-Planck-Institut für Plasmaphysik, Germany

J olan Moldvai, Reports Library, MTA KFKI-ATKI, Hungary

Dr. P. Kaw, Institute for Plasma Research, India

Ms. P.J . Pathak, Librarian, Insitute for Plasma Research, India

Ms. Clelia De Palo, Associazione EURATOM-ENEA, I taly

Dr. G. Grosso, Instituto di Fisica del Plasma, Italy

Librarian, Naka Fusion Research Establishment, J AERI, J apan

Library, Plasma Physics Laboratory, Kyoto University, J apan

Research Information Center, National Institute for Fusion Science, J apan

Dr. O. Mitarai, Kyushu Tokai University, J apan

Library, Academia Sinica, Institute of Plasma Physics, People's Republic of China

Shih-Tung Tsai, Institute of Physics, Chinese Academy of Sciences, People's Republic of China

Dr. S. Mirnov, TRINITI, Troitsk, Russian Federation, Russia

Dr. V.S. Strelkov, Kurchatov Institute, Russian Federation, Russia

Professor Peter Lukac, Katedra Fyziky Plazmy MFF UK, Mlynska dolina F-2, Komenskeho Univerzita, SK-842 15 Bratislava, Slovakia

Dr. G.S. Lee, Korea Basic Science Institute, South Korea

Mr. Dennis Bruggink, Fusion Library, University of Wisconsin, USA

Institute for Plasma Research, University of Maryland, USA

Librarian, Fusion Energy Division, Oak Ridge National Laboratory, USA

Librarian, Institute of Fusion Studies, University of Texas, USA

Librarian, Magnetic Fusion Program, Lawrence Livermore National Laboratory, USA

Library, General Atomics, USA

Plasma Physics Group, Fusion Energy Research Program, University of California at San Diego, USA

Plasma Physics Library, Columbia University, USA

Alkesh Punjabi, Center for Fusion Research and Training, Hampton University, USA

Dr. W.M. Stacey, Fusion Research Center, Georgia Institute of Technology, USA

Dr. J ohn Willis, U.S. Department of Energy, Office of Fusion Energy Sciences, USA

Mr. Paul H. Wright, Indianapolis, Indiana, USA 
The Princeton Plasma Physics Laboratory is operated by Princeton University under contract with the U.S. Department of Energy.

\author{
Information Services \\ Princeton Plasma Physics Laboratory \\ P.O. Box 451 \\ Princeton, NJ 08543
}

Phone: 609-243-2750

Fax: 609-243-2751

e-mail: pppl_info@pppl.gov

Internet Address: http://www.pppl.gov 